\title{
In Silico Investigation of Potential Pyruvate Kinase M2 Regulators from Traditional Chinese Medicine against Cancers
}

\author{
Kuan-Chung Chen, ${ }^{1}$ Kuen-Bao Chen, ${ }^{2,3,4}$ Hsin-Yi Chen, ${ }^{3}$ and Calvin Yu-Chian Chen ${ }^{2,3,5,6}$ \\ ${ }^{1}$ School of Pharmacy, China Medical University, Taichung 40402, Taiwan \\ ${ }^{2}$ School of Medicine, College of Medicine, China Medical University, Taichung 40402, Taiwan \\ ${ }^{3}$ Department of Biomedical Informatics, Asia University, Taichung 41354, Taiwan \\ ${ }^{4}$ Department of Anesthesiology, China Medical University Hospital, Taichung 40447, Taiwan \\ ${ }^{5}$ Human Genetic Center, Department of Medical Research, China Medical University Hospital, Taichung, Taiwan \\ ${ }^{6}$ Research Center for Chinese Medicine \& Acupuncture, China Medical University, Taichung 40402, Taiwan \\ Correspondence should be addressed to Calvin Yu-Chian Chen; ycc929@MIT.edu
}

Received 22 February 2014; Revised 5 March 2014; Accepted 5 March 2014; Published 25 June 2014

Academic Editor: Chung Y. Hsu

Copyright ( $) 2014$ Kuan-Chung Chen et al. This is an open access article distributed under the Creative Commons Attribution License, which permits unrestricted use, distribution, and reproduction in any medium, provided the original work is properly cited.

A recent research in cancer research demonstrates that tumor-specific pyruvate kinase M2 (PKM2) plays an important role in chromosome segregation and mitosis progression of tumor cells. To improve the drug development of TCM compounds, we aim to identify potent TCM compounds as lead compounds of PKM2 regulators. PONDR-Fit protocol was utilized to predict the disordered disposition in the binding domain of PKM2 protein before virtual screening as the disordered structure in the protein may cause the side effect and downregulation of the possibility of ligand to bind with target protein. MD simulation was performed to validate the stability of interactions between PKM2 proteins and each ligand after virtual screening. The top TCM compounds, saussureamine $\mathrm{C}$ and precatorine, extracted from Lycium chinense Mill. and Abrus precatorius L., respectively, have higher binding affinities with target protein in docking simulation than control. They have stable H-bonds with residues A:Lys311 and some other residues in both chains of PKM2 protein. Hence, we propose the TCM compounds, saussureamine C and precatorine, as potential candidates as lead compounds for further study in drug development process with the PKM2 protein against cancer.

\section{Introduction}

Recently, more and more pathogenesis of diseases has been identified $[1,2]$ to reveal potential target proteins for drug design [3-5]. A recent research in cancer research demonstrates that tumor-specific pyruvate kinase M2 (PKM2) plays an important role in chromosome segregation and mitosis progression of tumor cells $[6,7]$. PKM2 proteins can be treated as drug target proteins against cancers $[8,9]$.

The computer-aided drug design had wildly been used for virtual drug screening in the drug design $[10,11]$. In previous study, many compounds from traditional Chinese medicine
(TCM) have been identified as potential lead compounds in computer-aided drug design for the treatment of cancers [12-14], metabolic syndrome [15], diabetes [16], stroke [17, 18], inflammation [19], and some other diseases [20]. To improve the drug development of TCM compounds, we employed TCM compounds from TCM Database@Taiwan [21] to virtual screening of the potent lead compounds of PKM2 regulators. As the disordered structure in the protein may cause the side effect and downregulation of the possibility of ligand to bind with target protein [22], PONDR-Fit protocol was performed to predict the disordered disposition in binding domain of PKM2 protein before virtual screening. 


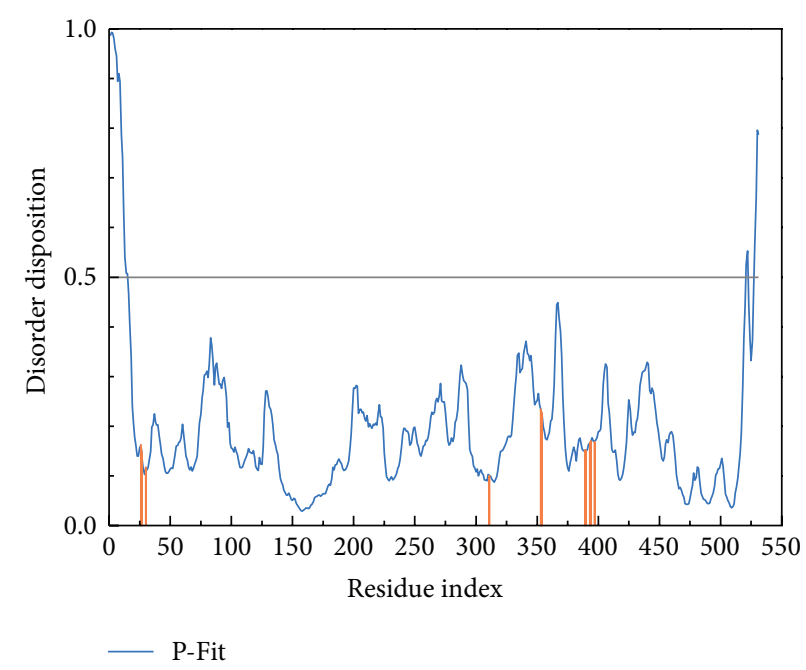

FIGURE 1: Disordered disposition predicted by PONDR-Fit.

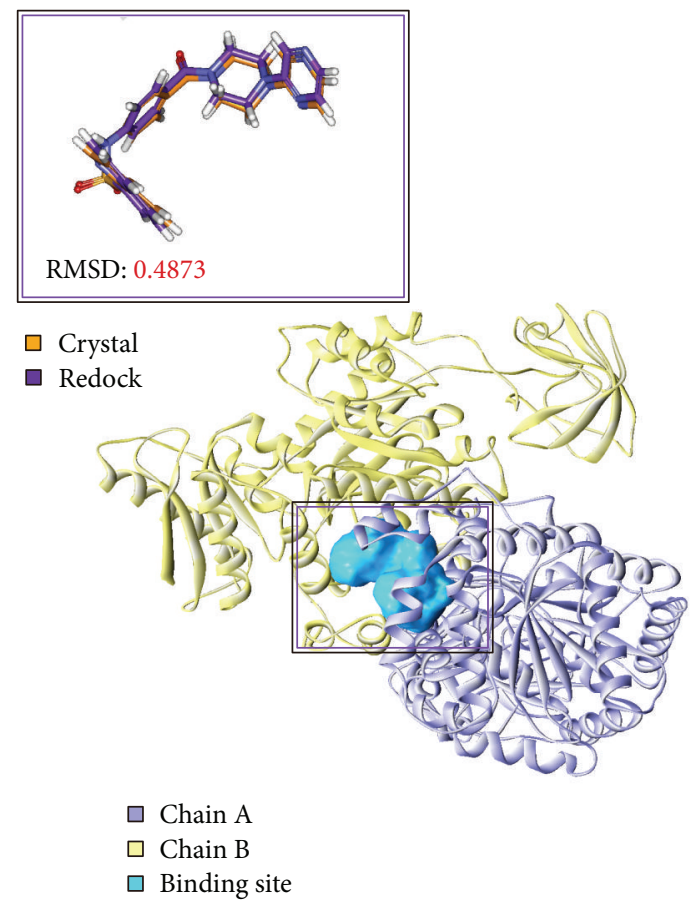

Figure 2: Binding site of PKM2 protein defined as the volume of $N$-(4-((4-(pyrazin-2-yl)piperazin-1-yl)carbonyl)phenyl)quinoline-8sulfonamide and root-mean-square deviation value between crystallized structure (orange) and docking pose (violet).

The MD simulation was performed after virtual screening, to validate the stability of interactions between PKM2 proteins and each ligand in each docking pose.

\section{Materials and Methods}

2.1. Data Collection. The X-ray crystallography structure of the human pyruvate kinase M2 (PKM2) was downloaded from RCSB Protein Data Bank with PDB ID: 4G1N [9]. To predict the disordered disposition in PKM2 protein, PONDR-Fit [23] protocol was employed with the sequence of PKM2 protein from Swiss-Prot (UniProtKB: P14618). In preparation section, the final structure of PKM2 protein was protonated with Chemistry at HARvard Macromolecular Mechanics (CHARMM) force field [24] and removed water molecules in the X-ray crystallography structure by Prepare 


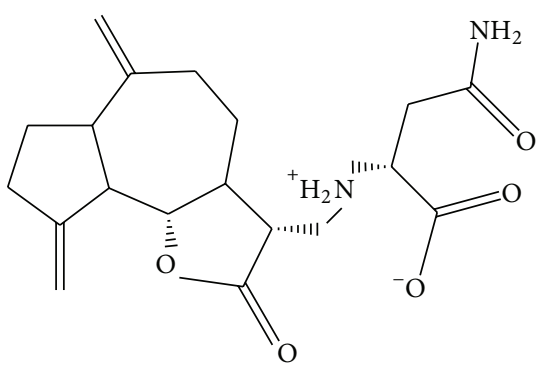

(a)

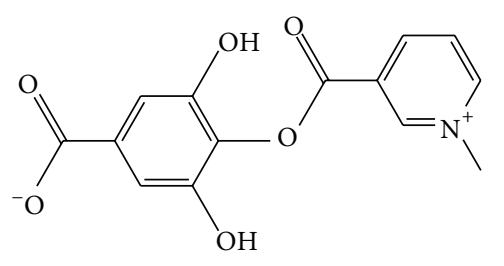

(b)

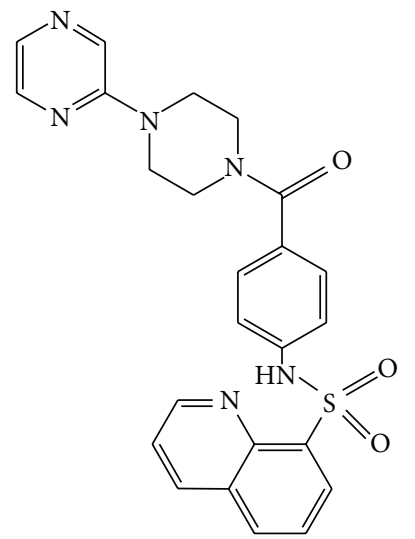

(c)

Figure 3: Chemical scaffold of controls and top two TCM candidates with their scoring function and sources. (a) Saussureamine C, (b) precatorine, and (c) NZT.

Protein module in Discovery Studio 2.5 (DS2.5). The TCM compounds from TCM Database@Taiwan [21] were filtered by Lipinski's Rule of Five [25], and their final structure was protonated using Prepare Ligand module in DS2.5. The binding site was defined by the volume of the cocrystallized PKM2 activator for virtual screening.

2.2. Docking Simulation. The TCM compounds were docking into the binding site defined above by LigandFit protocol [26] in DS 2.5 using a shape filter and Monte-Carlo ligand conformation generation. CHARMM force field [24] was employed to optionally minimize the docking poses, and then the clustering algorithm was employed to filter out the similar
TABLE 1: Scoring functions of top candidates from TCM database screening.

\begin{tabular}{lcc}
\hline Name & Source & Dock Score \\
\hline Saussureamine C & Lycium chinense Mill. & 166.382 \\
Precatorine & Abrus precatorius L. & 161.002 \\
NZT $^{*}$ & & 73.062 \\
\hline
\end{tabular}

${ }^{*}$ Control: $N$-(4-((4-(pyrazin-2-yl)piperazin-1-

yl)carbonyl)phenyl)quinoline-8-sulfonamide.

poses. Each docking pose was evaluated by Dock Score using the following equation:

Dock Score $=-($ ligand receptor interaction energy

$$
\text { +ligand internal energy). }
$$

2.3. Molecular Dynamics (MD) Simulation. The molecular dynamics (MD) simulation was employed with classical molecular dynamics theory using Gromacs 4.5.5 [27] to simulate the variation of each protein-ligand complex under dynamic conditions. In preparation section, the PKM2 proteins were prepared by pdb2gmx protocol of Gromacs to provide topology and parameters with CHARMM27 force field, and each ligand was prepared by SwissParam program [28] to provide topology and parameters with CHARMM. A cubic box solvated using TIP3P water model and $0.145 \mathrm{M}$ $\mathrm{NaCl}$ model was defined based upon the edge approx. $12 \AA$ from the protein complexes periphery. In the minimization section, we employed steepest descents [29] minimization with a maximum of 5,000 steps to remove bad van der Waals contacts. In the equilibration section, we perform positionrestrained molecular dynamics with the linear constraint algorithm for all bonds by Gromacs program with NVT equilibration, Particle Mesh Ewald method, and Berendsen weak thermal coupling method. In the production section, we perform $10,000 \mathrm{ps}$ production simulation by Gromacs program with time step in unit of $2 \mathrm{fs}$ under NPT ensembles and particle mesh Ewald (PME) option. A series of protocols in Gromacs program was employed to analyze the MD trajectories of 5000 ps.

\section{Results and Discussion}

3.1. Disordered Protein Prediction. The disordered disposition predicted by PONDR-Fit protocol with the sequence of PKM2 protein from Swiss-Prot (UniProtKB: P14618) was displayed in Figure 1. The key residues in the binding site do not locate in disordered domain $(>0.5)$, which indicates that PKM2 protein expresses a stable binding domain in protein folding. We employed the crystallography structure of PKM2 protein for docking simulation as the residues in the binding site of target protein have no significant variation.

3.2. Docking Simulation. To validate the accuracy of LigandFit protocol in DS2.5, the cocrystallized PKM2 protein activator was redocked into the binding site of PKM2 


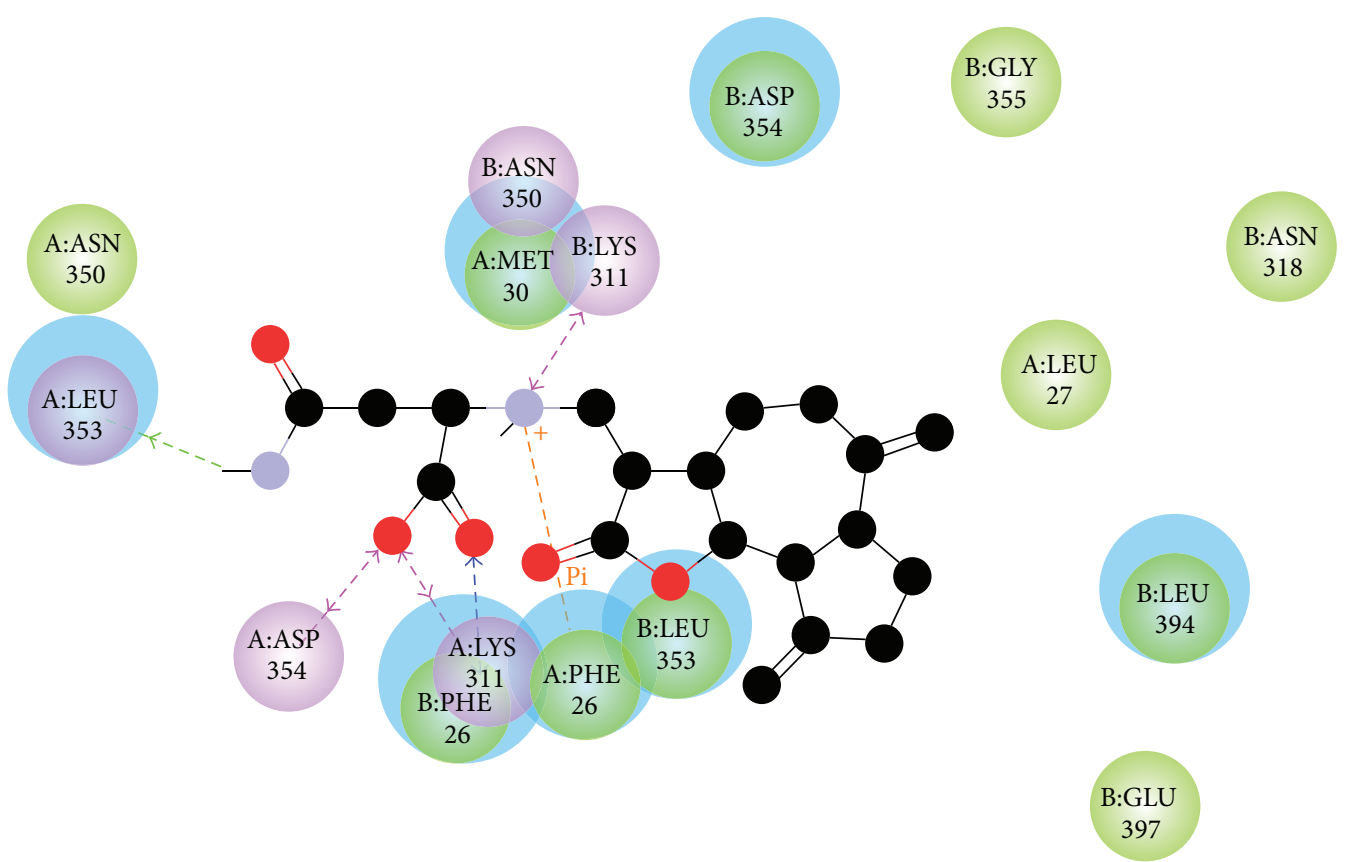

B:GLN B:TYR

$393 \quad 390$

(a)

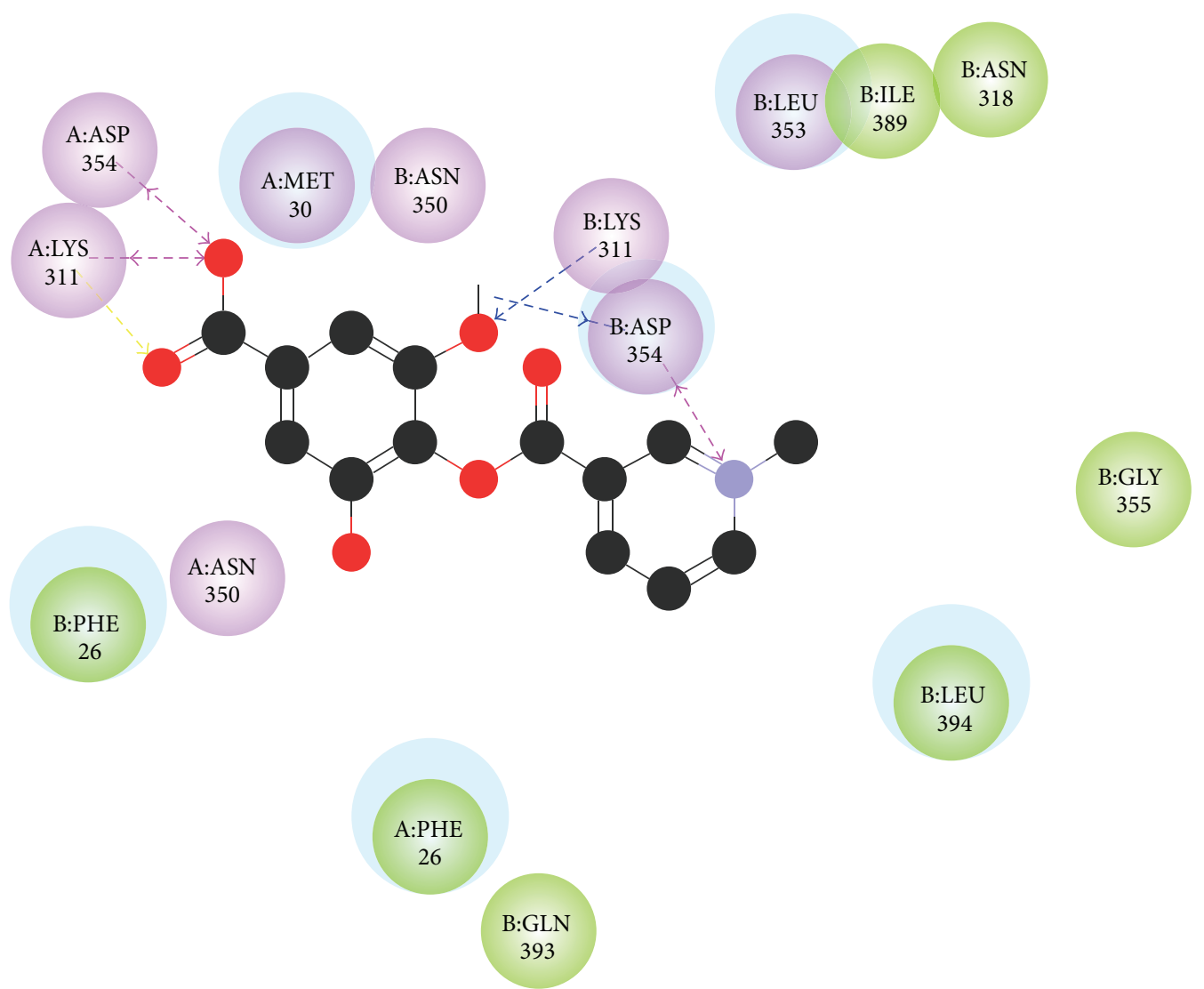

(b)

FIgure 4: Continued. 


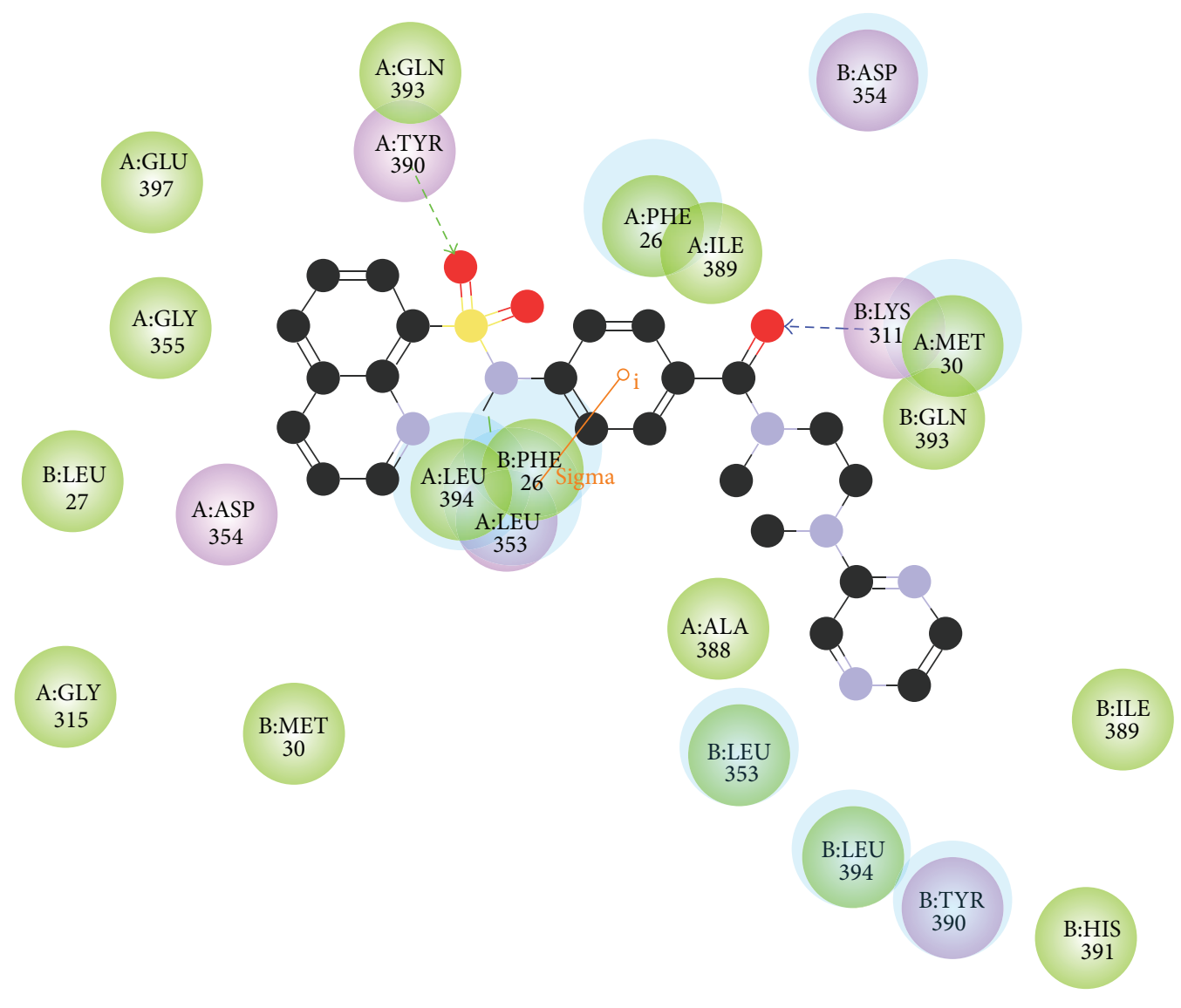

(c)

FIGURE 4: Docking pose of PKM2 protein complex with (a) saussureamine C, (b) precatorine, and (c) NZT.

protein. The root-mean-square deviation (RMSD) value between crystallized structure and docking pose of control is 0.4873 (Figure 2), which shows a good accuracy in the docking simulation by LigandFit protocol. So we employ LigandFit protocol as suitable for virtual screening with PKM2 protein. The top TCM compounds ranked by Dock Score [26] and control, N-(4-((4-(pyrazin-2-yl)piperazin1-yl)carbonyl)phenyl)quinoline-8-sulfonamide (NZT), are shown in Table 1. For the top two TCM compounds, saussureamine $\mathrm{C}$ and precatorine were extracted from Lycium chinense Mill. and Abrus precatorius L. The chemical scaffold of saussureamine $\mathrm{C}$, precatorine, and control is illustrated in Figure 3. According to the docking poses in Figures 4 and 5 , the top two candidate compounds have hydrogen bonds (H-bonds) with common residue B:Lys311 and an interaction with residues in both chains of PKM2 protein as control.

3.3. Molecular Dynamics Simulation. LigandFit protocol performs a docking simulation with a rigid body of PKM2 proteins. The docking poses with PKM2 protein may modify under dynamic conditions. We employed the MD simulation to validate the stability of interactions of each ligand with PKM2 proteins. Root-mean-square deviations (RMSDs) illustrated the atomic fluctuations during MD simulation. Figure 6 displays the atomic fluctuations of PKM2 proteins and ligands in complexes with saussureamine $\mathrm{C}$, precatorine, and control during 10,000 ps $\mathrm{MD}$ simulation. It shows that PKM2 proteins tend to be stable after a short period of MD simulation. In addition, there is no significant variance for the total energies of each PKM2 protein complex during MD simulation (Figure 7). The variation and distribution of radii of gyration for protein and ligand over 10,000 ps MD simulation in Figure 8 indicate that the radii of gyration of PKM2 protein complexes with ligands, saussureamine $\mathrm{C}$, precatorine, and control were stabilized under dynamics condition after $5,000 \mathrm{ps} \mathrm{MD}$ simulation. The variation of mean-square displacement (MSD) and total solvent accessible surface area (SASA) for each protein and ligand displayed in Figure 9. They indicate that the SASA of PKM2 protein in complexes with precatorine was decreased after MD simulation, which implies that precatorine may cause two chains of PKM2 protein more compact. Root-mean-square fluctuations (RMSFs) for each residue over 10,000 ps MD simulation are shown in Figure 10. They indicate that PKM2 proteins docking with saussureamine $\mathrm{C}$ and precatorine cause flexibility for PKM2 proteins as control. 


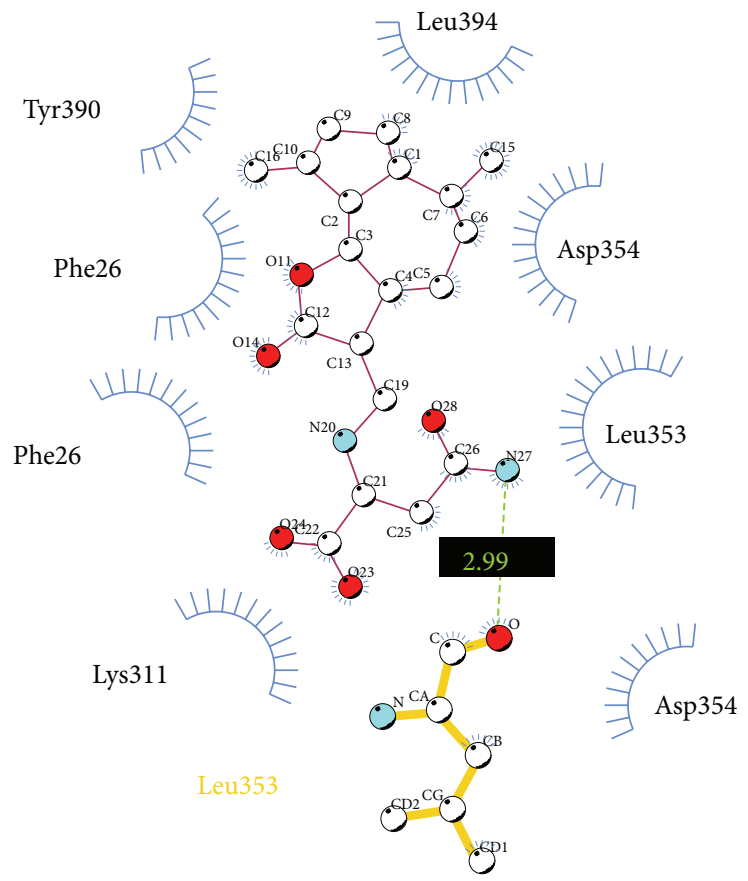

(a)
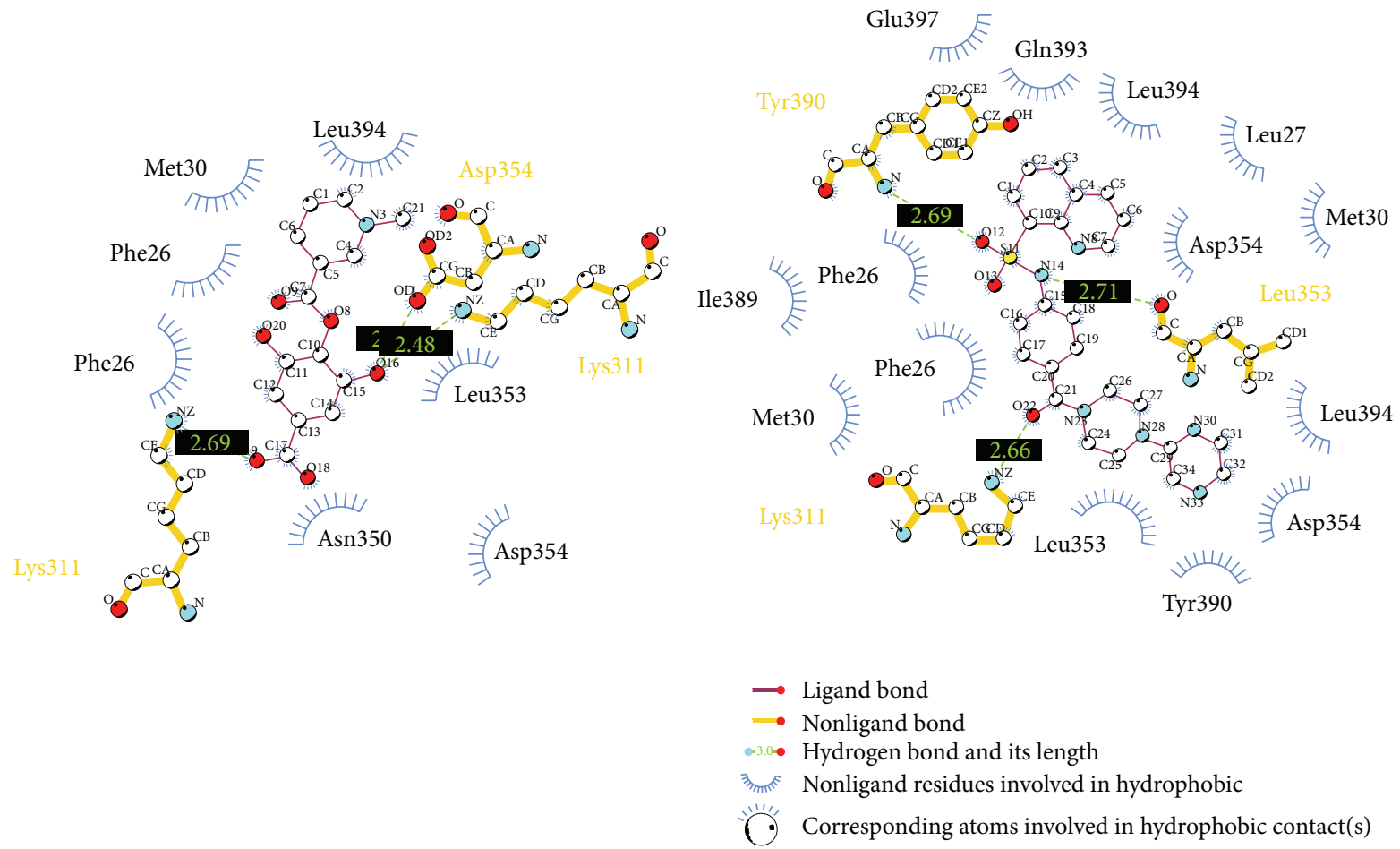

(b)

(c)

FIGURE 5: Docking pose of PKM2 protein complex with (a) saussureamine C, (b) precatorine, and (c) NZT drawn by LIGPLOT program. 


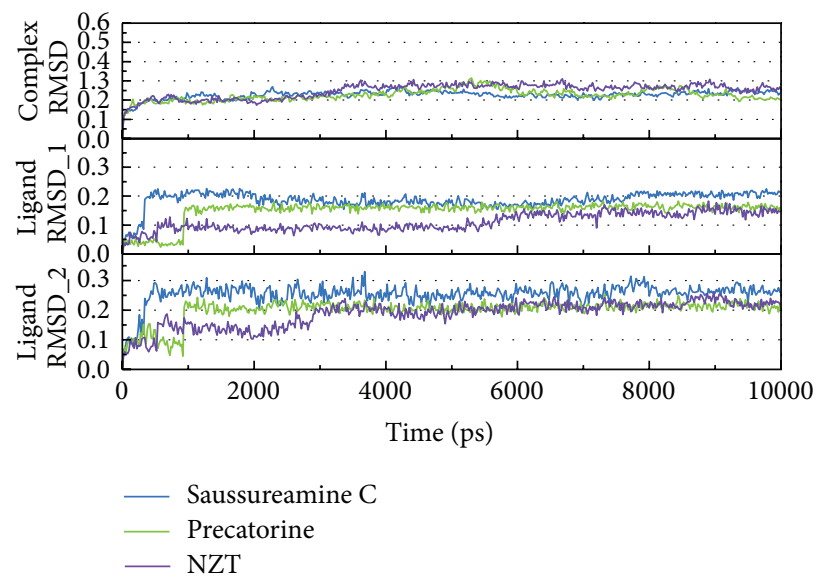

FIGURE 6: Root-mean-square deviations in units of nm for protein and ligand for PKM2 protein complexes with saussureamine C, precatorine, and NZT. Ligand RMSD_1 and Ligand RMSD_2 are calculated with least squares fit by protein and ligand, respectively.

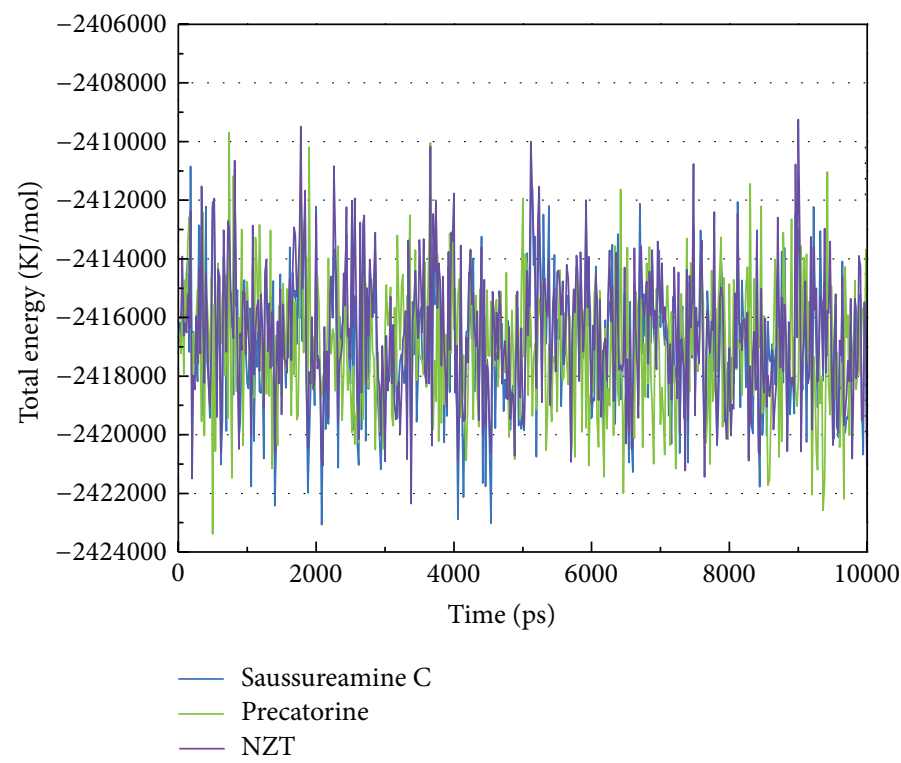

(a)

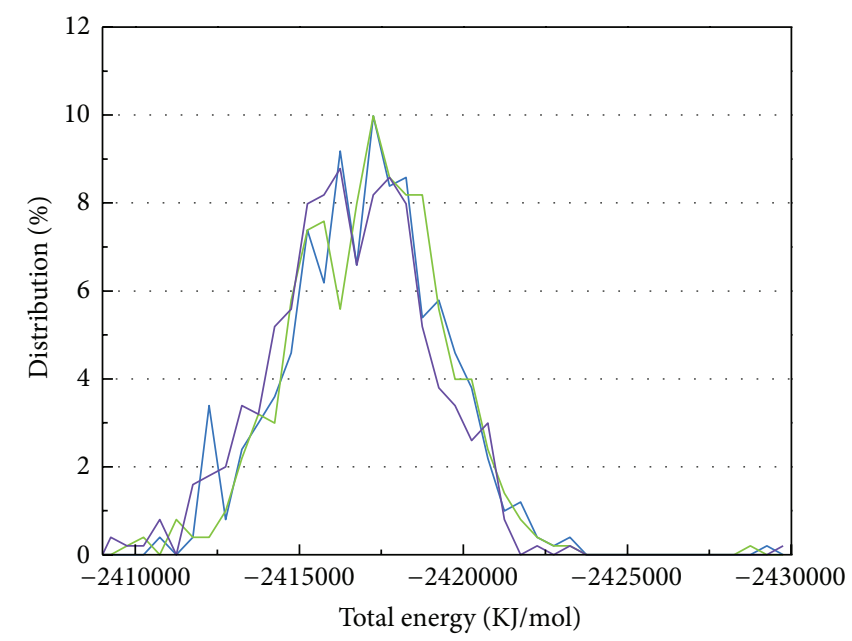

(b)

FIgURE 7: (a) Distribution and (b) variation of total energy for PKM2 protein complexes with saussureamine C, precatorine, and NZT over 5000 ps of MD simulation. 


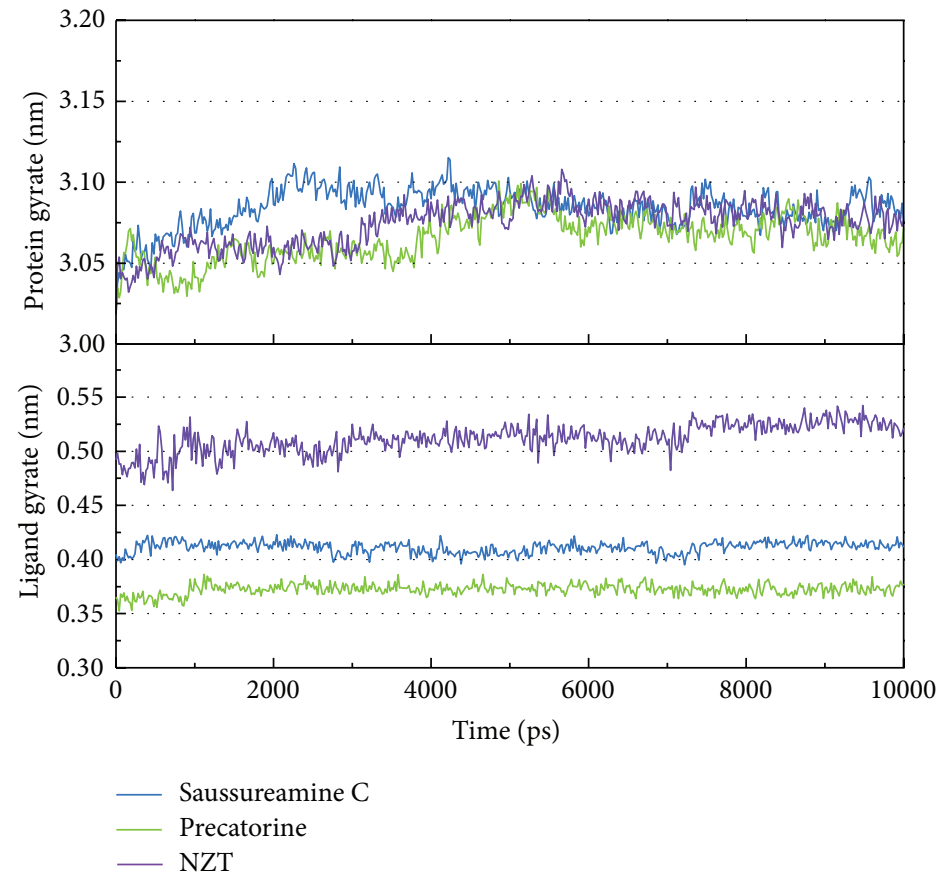

(a)

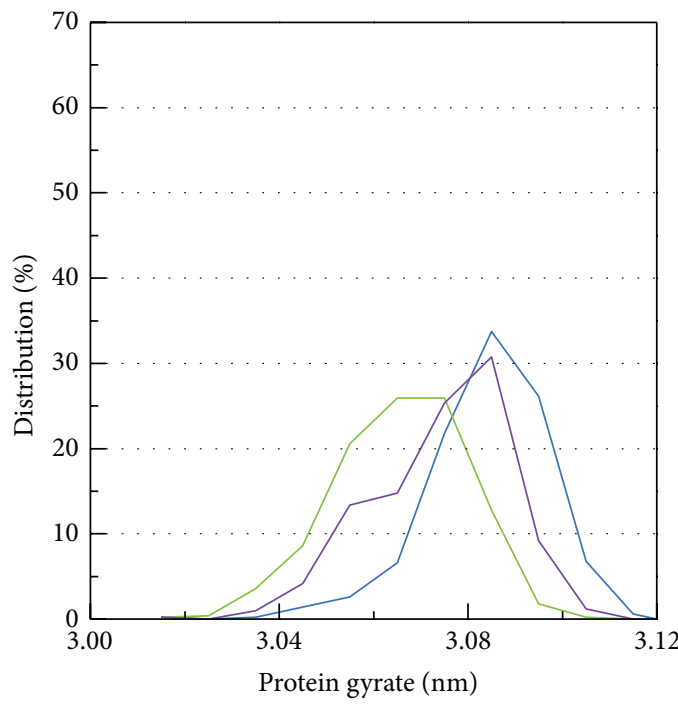

(b)

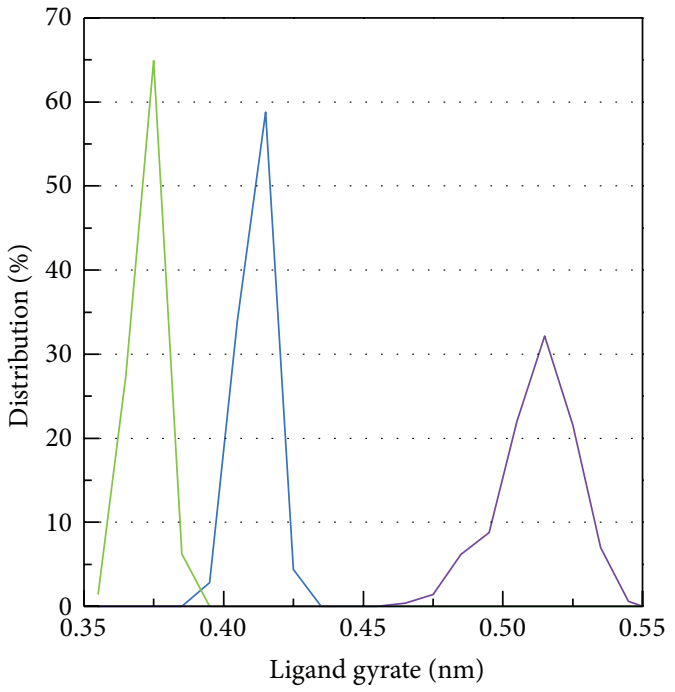

(c)

FIGURE 8: (a) Variation of radii of gyration for protein and ligands in PKM2 complexes with saussureamine C, precatorine, and NZT over 5000 ps of MD simulation. Distribution of radii of gyration for (b) protein and (c) ligands in PKM2 complexes with saussureamine C, precatorine, and NZT over 10,000 ps of MD simulation.

After MD simulation, we decide the representative structures of PKM2 protein complexes by the RMSD values and graphical depiction of the clusters analysis with cutoff of $0.1 \mathrm{~nm}$ (Figure 11). To compare with the interactions in docking simulation and in representative structures of PKM2 protein complexes after MD simulation, the snapshots of each docking pose were displayed in Figure 12. They indicate that two TCM candidates remain the $\mathrm{H}$-bonds with residues Lys311 in chain A of PKM2 protein. Table 2 and Figure 13 display the H-bond occupancy and distance variation for each ligand with PKM2 proteins. They indicate that both TCM compounds have stable H-bonds with residues A:Lys311 


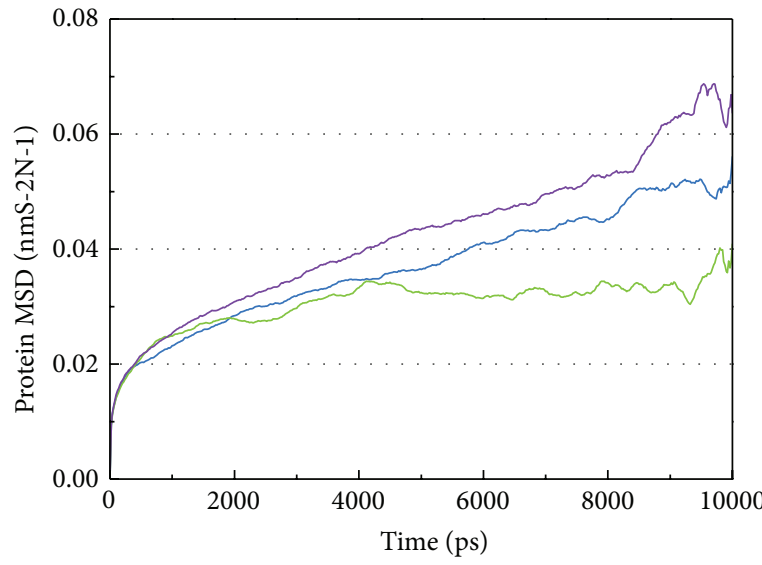

(a)

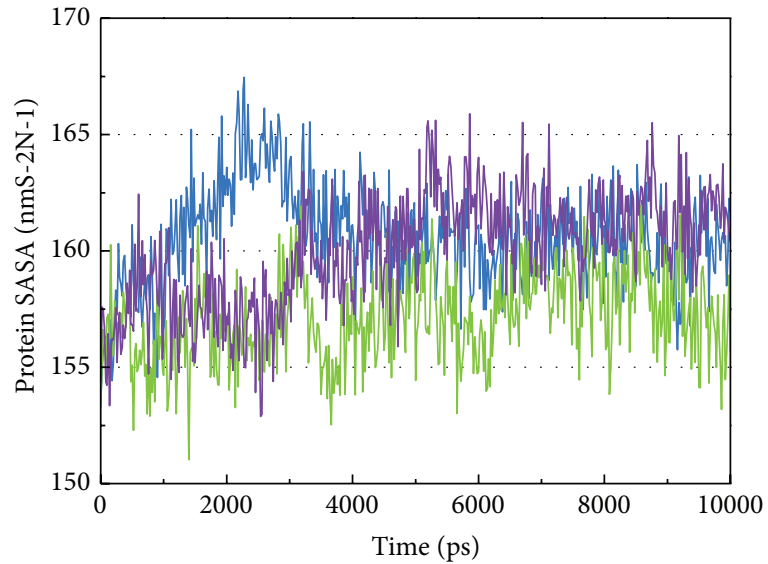

(c)

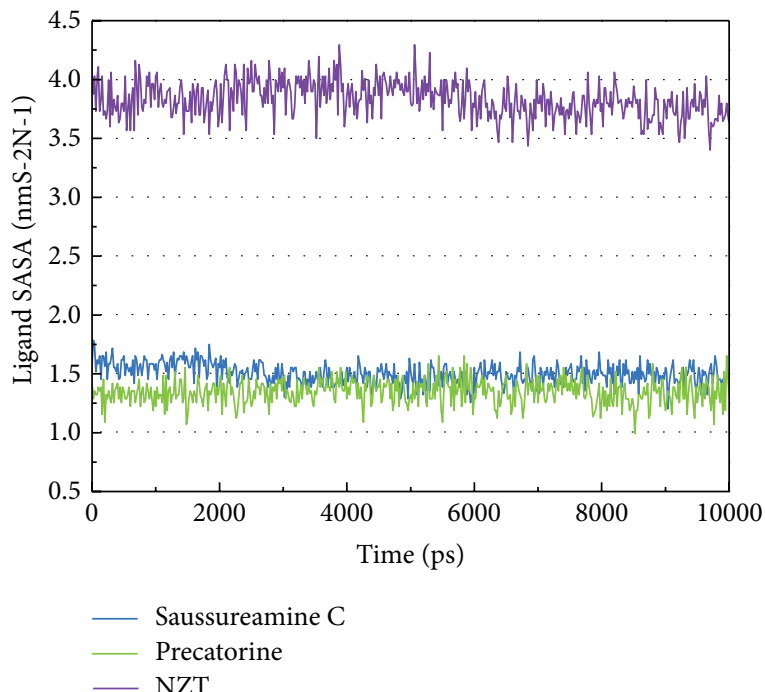

(e)

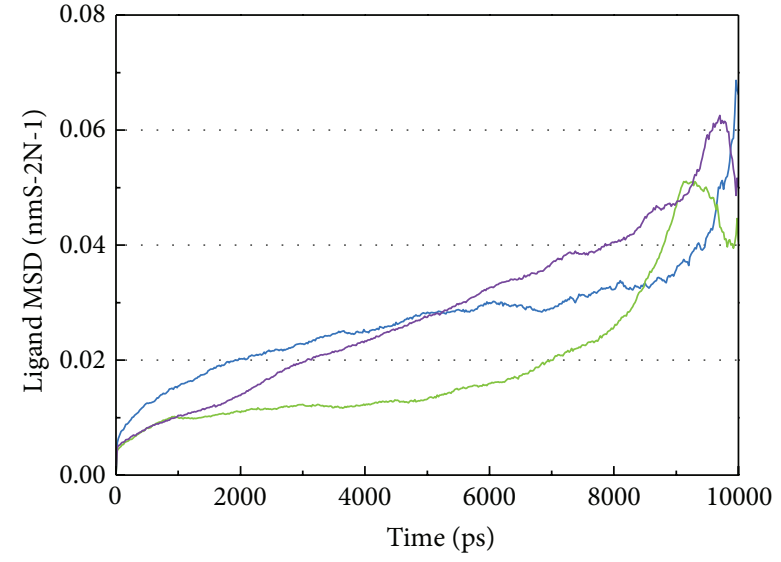

(b)

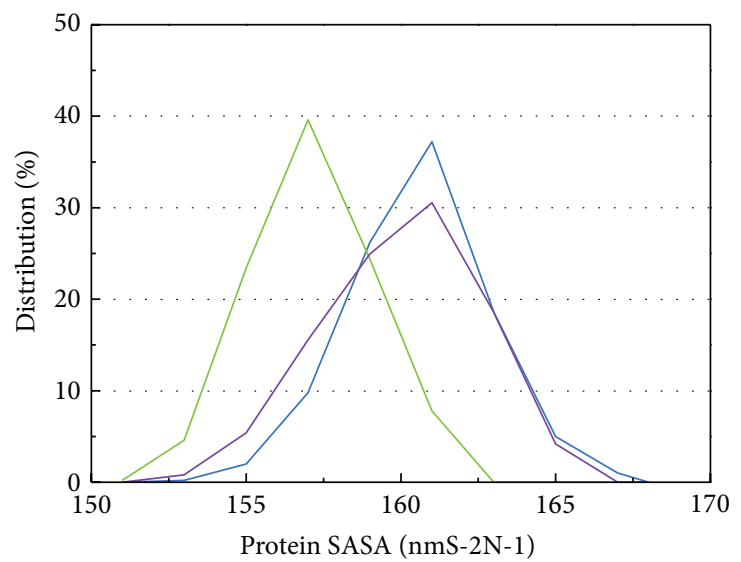

(d)

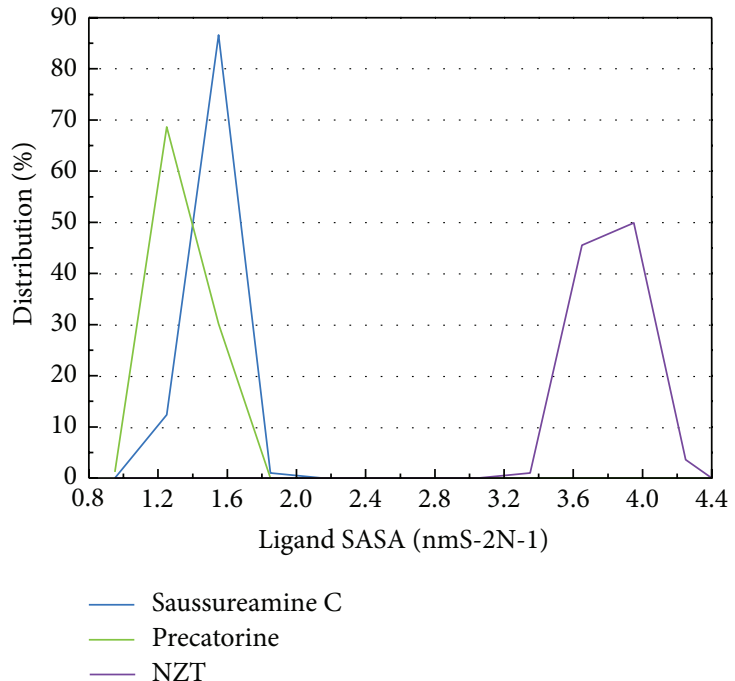

(f)

FIGURE 9: Variation of (a) mean square displacement (MSD) of protein, (b) ligand MSD, (c) total solvent accessible surface area (SASA) of protein, and (e) ligand SASA and distribution of (d) protein SASA and (f) ligand SASA for PKM2 complexes with saussureamine C, precatorine, and NZT over 10,000 ps of MD simulation. 


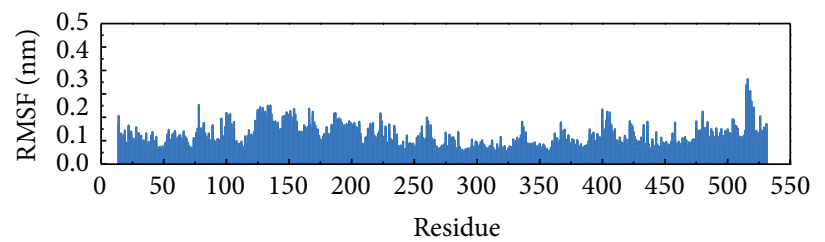

Saussureamine C

(a)

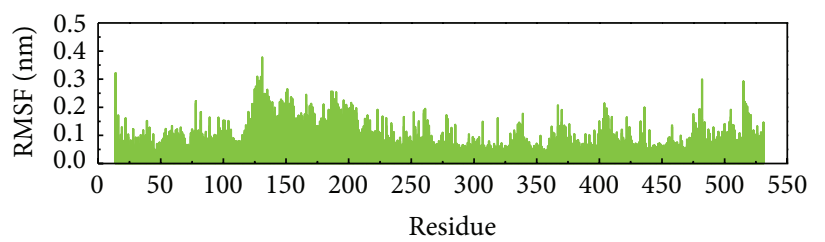

Precatorine

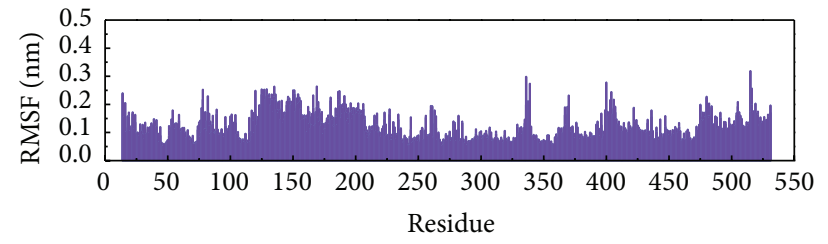

NZT

(b)

(c)

FIGURE 10: Root-mean-square fluctuation (RMSF) for residues in PKM2 complexes with saussureamine C, precatorine, and NZT.

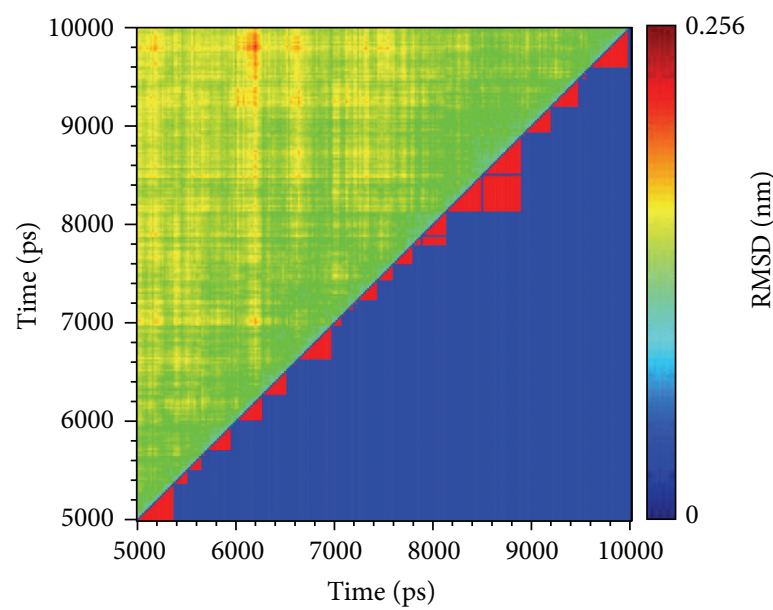

(a)

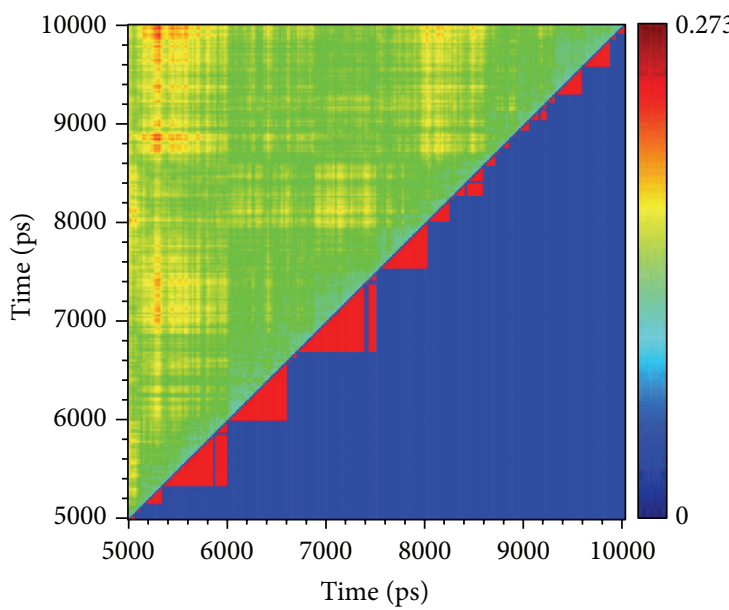

(b)

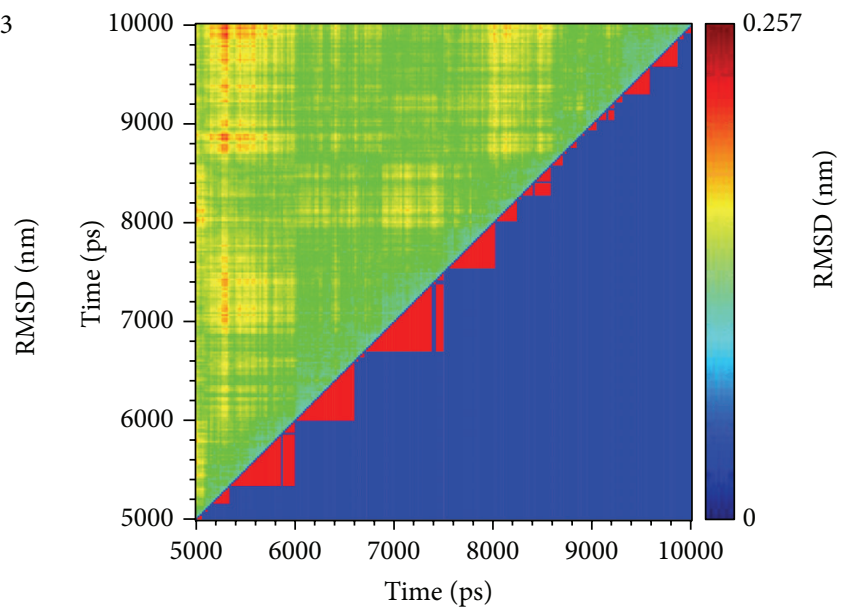

(c)

FIGURE 11: Root-mean-square deviation value (upper left half) and graphical depiction of the clusters with cutoff $0.1 \mathrm{~nm}$ (lower right half) for PKM2 complexes with (a) saussureamine C, (b) precatorine, and (c) NZT. 


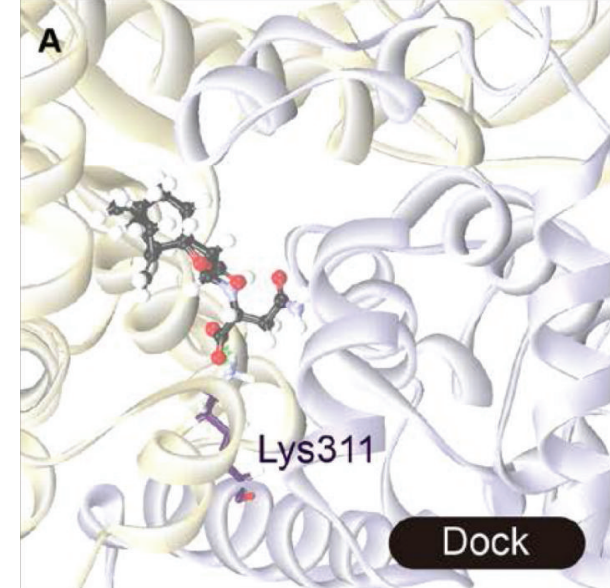

(a)

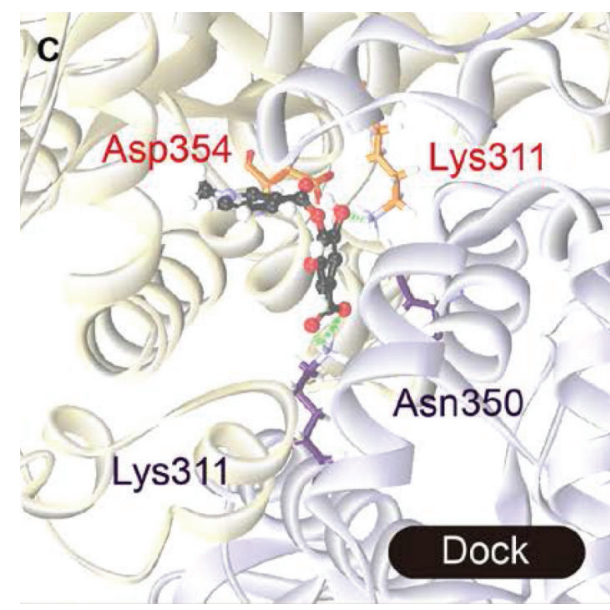

(c)

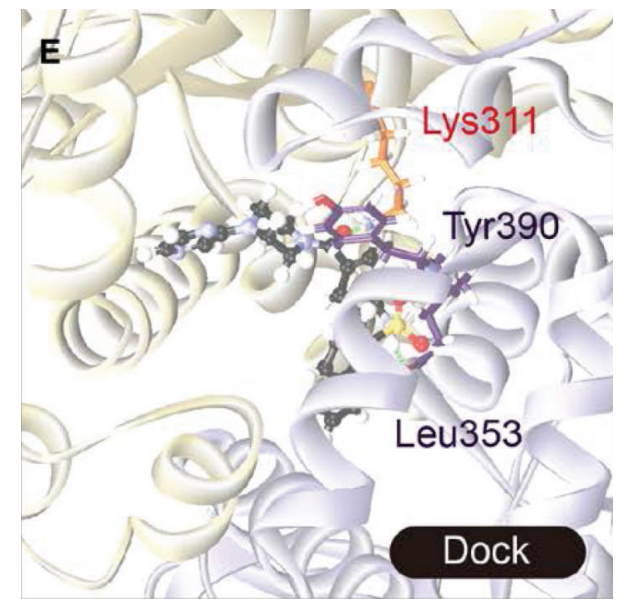

(e)

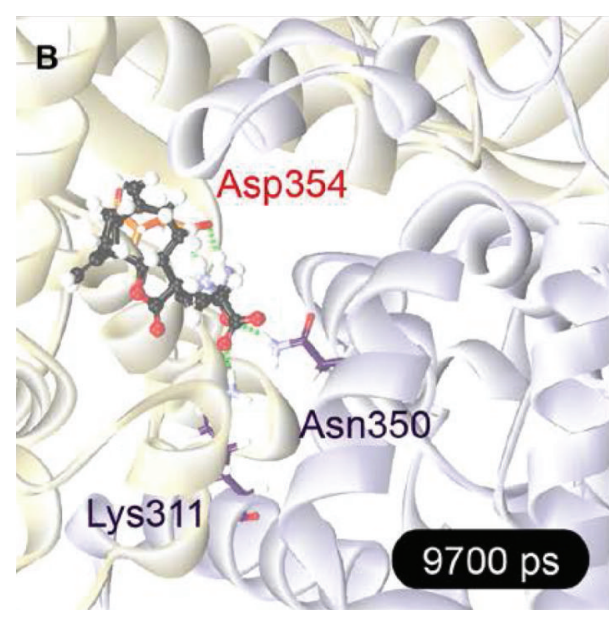

(b)

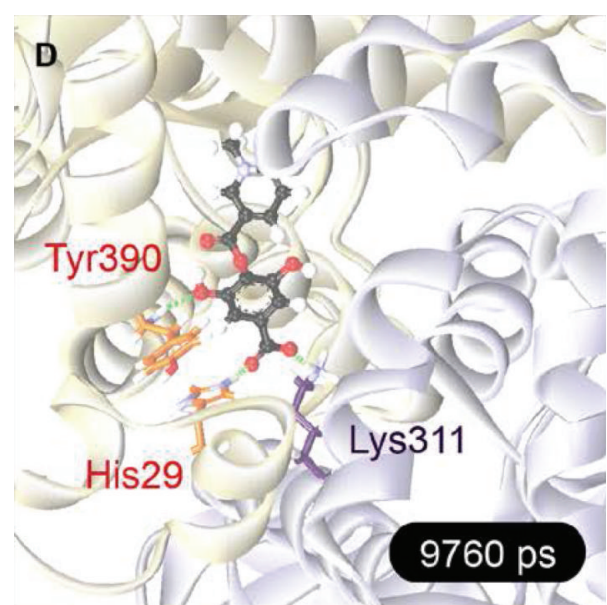

(d)

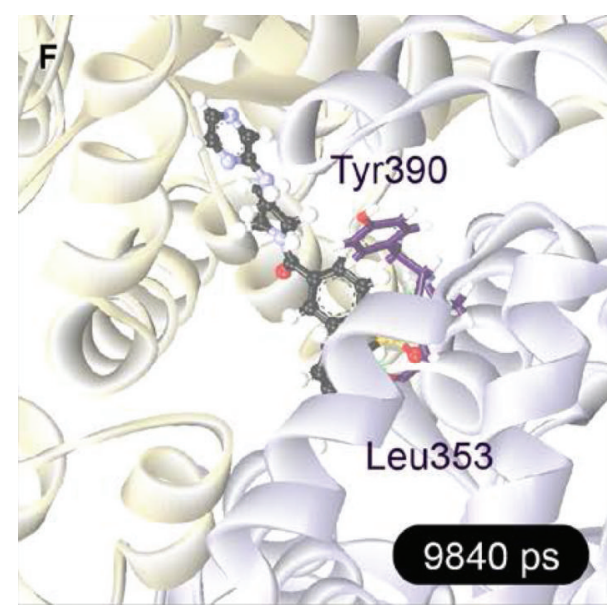

(f)

FIGURE 12: Docking poses in docking simulation (left) and middle RMSD structure in the major cluster (right) for PKM2 complexes with (a), (b) saussureamine $C,(c)$, (d) precatorine, and (e), (f) NZT. 


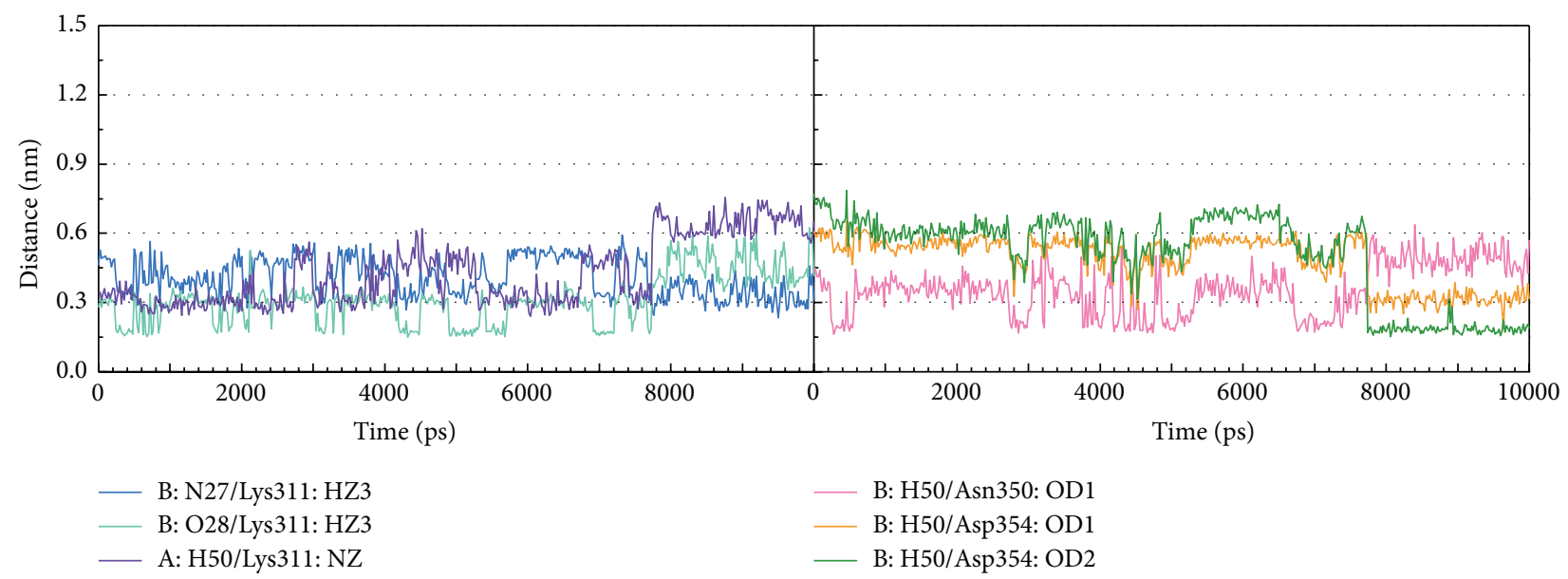

(a)

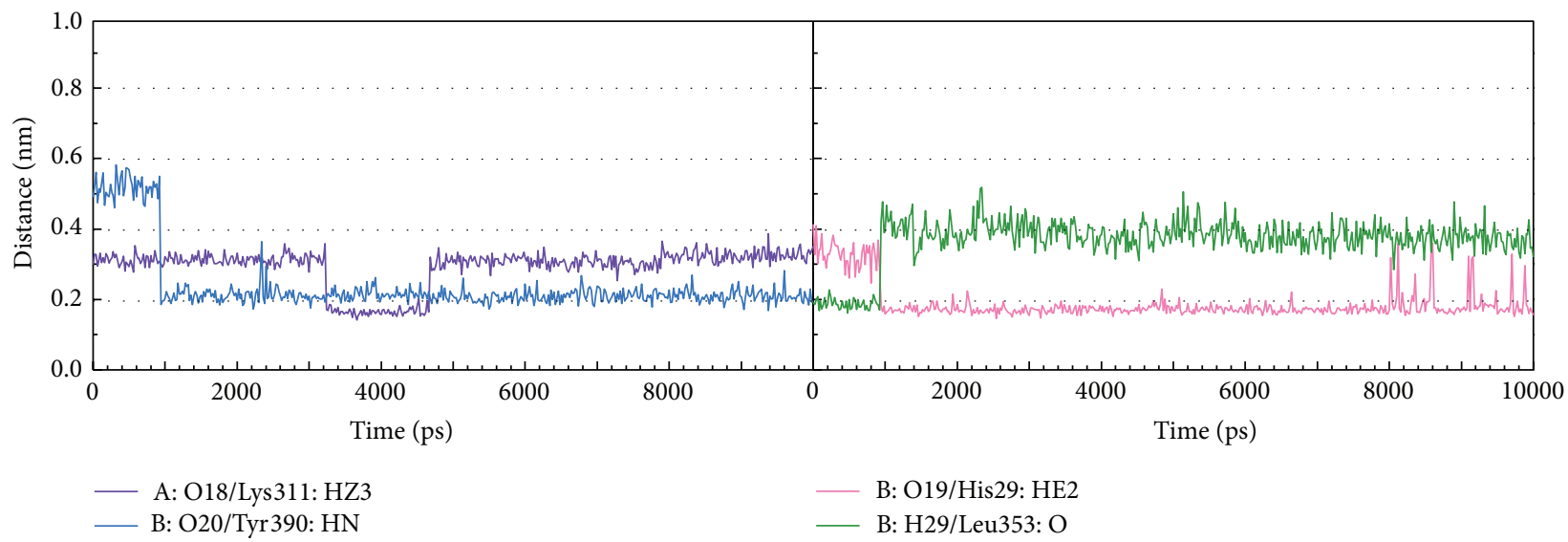

(b)

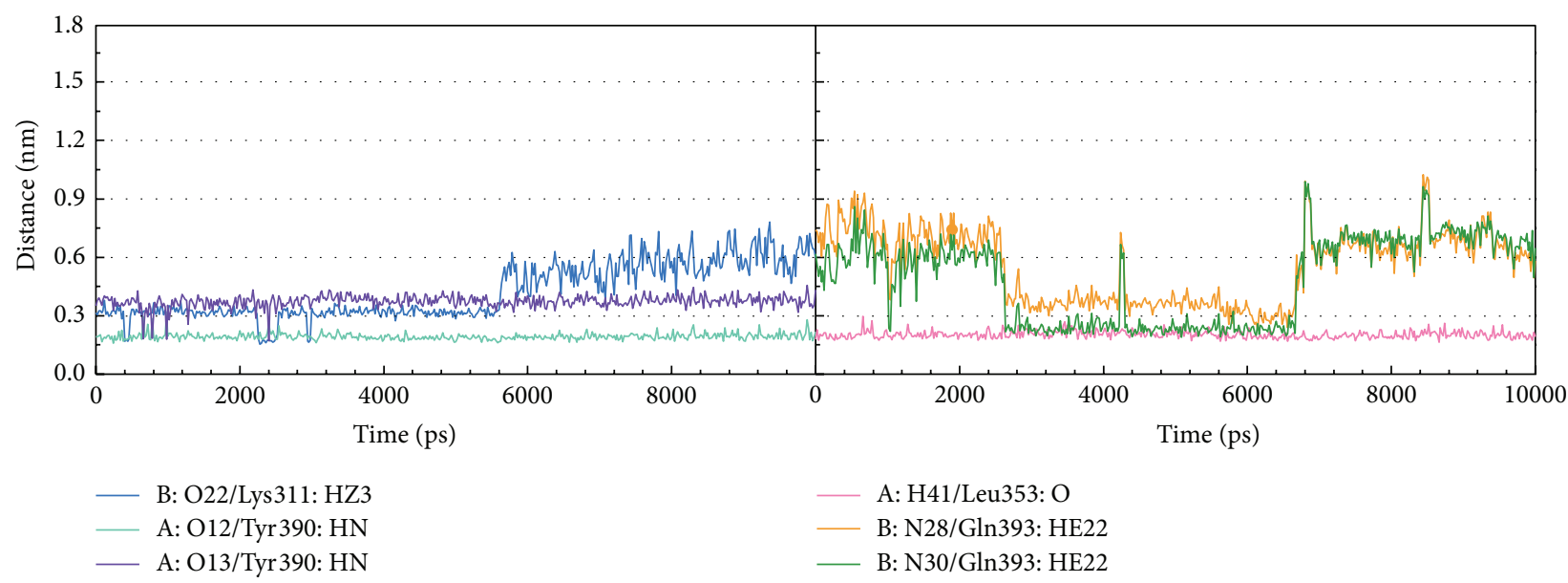

(c)

Figure 13: Distance variation of H-bonds with PKM2 protein during MD simulation. (a) Saussureamine C, (b) precatorine, and (c) NZT. 
TABLE 2: H-bond occupancy for key residues of PKM2 protein with top TCM compounds overall 10,000 ps of molecular dynamics simulation.

\begin{tabular}{|c|c|c|c|c|c|c|c|}
\hline \multirow{2}{*}{ Ligand } & \multirow{2}{*}{ H-bond } & \multirow{2}{*}{ Ligand atoms } & \multirow{2}{*}{ Amino acid } & \multicolumn{3}{|c|}{ Distance (nm) } & \multirow{2}{*}{ Occupancy (\%) } \\
\hline & & & & Max. & Min. & Average & \\
\hline \multirow{10}{*}{ Saussureamine C } & 1 & $\mathrm{O} 23$ & A:Lys311:HZ3 & 0.553 & 0.259 & 0.438 & $15.80 \%$ \\
\hline & 2 & $\mathrm{O} 24$ & A:Lys311:HZ3 & 0.57 & 0.146 & 0.294 & $94.80 \%$ \\
\hline & 3 & $\mathrm{~N} 27$ & A:Lys311:HZ3 & 0.593 & 0.234 & 0.408 & $30.00 \%$ \\
\hline & 4 & $\mathrm{O} 28$ & B:Lys311:HZ3 & 0.726 & 0.161 & 0.519 & $10.40 \%$ \\
\hline & 5 & $\mathrm{O} 28$ & B:Lys311:HZ3 & 0.63 & 0.15 & 0.31 & $73.20 \%$ \\
\hline & 6 & $\mathrm{H} 50$ & B:Lys311:NZ & 0.76 & 0.24 & 0.43 & $46.20 \%$ \\
\hline & 7 & $\mathrm{H} 50$ & A:Asn350:OD1 & 0.64 & 0.16 & 0.36 & $44.80 \%$ \\
\hline & 8 & $\mathrm{H} 52$ & B:Asp354:OD1 & 0.54 & 0.27 & 0.31 & $96.20 \%$ \\
\hline & 9 & $\mathrm{H} 50$ & B:Asp354:OD1 & 0.66 & 0.19 & 0.49 & $20.40 \%$ \\
\hline & 10 & $\mathrm{H} 50$ & B:Asp354:OD2 & 0.79 & 0.15 & 0.51 & $23.20 \%$ \\
\hline \multirow{4}{*}{ Precatorine } & 1 & $\mathrm{O} 18$ & A:Lys311:HZ3 & 0.39 & 0.14 & 0.29 & $98 \%$ \\
\hline & 2 & O19 & B:His29:HE2 & 0.41 & 0.15 & 0.19 & $97 \%$ \\
\hline & 3 & $\mathrm{O} 20$ & B:Tyr390:HN & 0.58 & 0.17 & 0.24 & $91 \%$ \\
\hline & 4 & $\mathrm{H} 29$ & B:Leu353:O & 0.52 & 0.16 & 0.37 & $25 \%$ \\
\hline \multirow{6}{*}{$\mathrm{NZT}^{*}$} & 1 & $\mathrm{O} 12$ & A:Tyr390:HN & 0.32 & 0.16 & 0.19 & $100 \%$ \\
\hline & 2 & $\mathrm{O} 13$ & A:Tyr390:HN & 0.46 & 0.17 & 0.37 & $15 \%$ \\
\hline & 3 & $\mathrm{O} 22$ & B:Lys311:HZ3 & 0.78 & 0.15 & 0.42 & $53 \%$ \\
\hline & 4 & $\mathrm{~N} 28$ & B:Gln393:HE22 & 1.03 & 0.23 & 0.56 & $18 \%$ \\
\hline & 5 & N30 & B:Gln393:HE22 & 0.99 & 0.19 & 0.49 & $40 \%$ \\
\hline & 6 & $\mathrm{H} 41$ & A:Leu353:O & 0.30 & 0.16 & 0.20 & $100 \%$ \\
\hline
\end{tabular}

H-bond occupancy cutoff: $0.35 \mathrm{~nm}$.

${ }^{*}$ Control: $N$-(4-((4-(pyrazin-2-yl)piperazin-1-yl)carbonyl)phenyl)quinoline-8-sulfonamide.

and some other residues in both chains of PKM2 protein, which can stabilize the docking poses in the binding domain.

\section{Conclusion}

This study aims to investigate the potent lead drug from TCM compounds for PKM2 protein inhibitors against cancers. The top TCM compounds, saussureamine $\mathrm{C}$ and precatorine, have higher binding affinities with PKM2 proteins in docking simulation than control. They have $\mathrm{H}$-bonds with residues A:Lys311 and some other residues in both chains of PKM2 protein. After MD simulation, the top TCM compounds maintain the similar docking poses under dynamic conditions. In addition, the top two TCM compounds, saussureamine $\mathrm{C}$ and precatorine, were extracted from Lycium chinense Mill. and Abrus precatorius L., respectively. Hence, we propose the TCM compounds, saussureamine $\mathrm{C}$ and precatorine, as potential candidates as lead compounds for further study in drug development process with the PKM2 protein against cancer.

\section{Conflict of Interests}

The authors declare that there is no conflict of interests.

\section{Authors' Contribution}

Kuan-Chung Chen, Kuen-Bao Chen, and Hsin-Yi Chen contributed equally to this work.

\section{Acknowledgments}

The research was supported by Grants from the National Science Council of Taiwan (NSC102-2325-B039-001 and NSC102-2221-E-468-027-), Asia University (ASIA100-CMU2, ASIA101-CMU-2, and 102-ASIA-07), and China Medical University Hospital (DMR-103-058, DMR-103-001, and DMR-103-096). This study is also supported in part by Taiwan Department of Health Clinical Trial and Research Center of Excellence (DOH102-TD-B-111-004), Taiwan Department of Health Cancer Research Center of Excellence (MOHW103TD-B-111-03), and CMU under the Aim for Top University Plan of the Ministry of Education, Taiwan.

\section{References}

[1] Y.-M. Chang, B. K. Velmurugan, W. W. Kuo et al., "Inhibitory effect of alpinate Oxyphyllae fructus extracts on Ang IIinduced cardiac pathological remodeling-related pathways in H9c2 cardiomyoblast cells," BioMedicine, vol. 3, no. 4, pp. 148152,2013

[2] Y. M. Leung, K. L. Wong, S. W. Chen et al., "Down-regulation of voltage-gated $\mathrm{Ca} 2+$ channels in $\mathrm{Ca} 2+$ store-depleted rat 
insulinoma RINm5F cells," BioMedicine, vol. 3, no. 3, pp. 130139, 2013.

[3] M. A. Leissring, E. Malito, S. Hedouin et al., "Designed inhibitors of insulin-degrading enzyme regulate the catabolism and activity of insulin," PLOS ONE, vol. 5, no. 5, Article ID e10504, 2010.

[4] M.-C. Lin, S.-Y. Tsai, F.-Y. Wang et al., "Leptin induces cell invasion and the upregulation of matrilysin in human colon cancer cells," BioMedicine, vol. 3, no. 4, pp. 174-180, 2013.

[5] V. Janssens and J. Goris, "Protein phosphatase 2A: a highly regulated family of serine/threonine phosphatases implicated in cell growth and signalling," Biochemical Journal, vol. 353, no. 3, pp. 417-439, 2001.

[6] Y. Jiang, X. Li, W. Yang et al., "PKM2 regulates chromosome segregation and mitosis progression of tumor cells," Molecular Cell, vol. 53, no. 1, pp. 75-87, 2014.

[7] H. R. Christofk, M. G. Vander Heiden, M. H. Harris et al., "The M2 splice isoform of pyruvate kinase is important for cancer metabolism and tumour growth," Nature, vol. 452, no. 7184, pp. 230-233, 2008.

[8] D. Anastasiou, Y. Yu, W. J. Israelsen et al., "Pyruvate kinase M2 activators promote tetramer formation and suppress tumorigenesis," Nature Chemical Biology, vol. 8, no. 10, pp. 839-847, 2012.

[9] C. Kung, J. Hixon, S. Choe et al., "Small molecule activation of pkm2 in cancer cells induces serine auxotrophy," Chemistry and Biology, vol. 19, no. 9, pp. 1187-1198, 2012.

[10] C. Y.-C. Chen, "A novel integrated framework and improved methodology of computer-aided drug design," Current Topics in Medicinal Chemistry, vol. 13, no. 9, pp. 965-988, 2013.

[11] H. J. Huang, H. W. Yu, C. Y. Chen et al., "Current developments of computer-aided drug design," Journal of the Taiwan Institute of Chemical Engineers, vol. 41, no. 6, pp. 623-635, 2010.

[12] C. Y. Chen and C. Y. C. Chen, "Insights into designing the dual-targeted HER2/HSP90 inhibitors," Journal of Molecular Graphics and Modelling, vol. 29, no. 1, pp. 21-31, 2010.

[13] S. C. Yang, S. S. Chang, H. Y. Chen, and C. Y. C. Chen, "Identification of potent EGFR inhibitors from TCM Database@Taiwan," PLoS Computational Biology, vol. 7, no. 10, Article ID e1002189, 2011.

[14] Y. A. Tsou, K. C. Chen, H. C. Lin, S. S. Chang, and C. Y. C. Chen, "Uroporphyrinogen decarboxylase as a potential target for specific components of traditional chinese medicine: a virtual screening and Molecular Dynamics Study," PLoS ONE, vol. 7, no. 11, Article ID e50087, 2012.

[15] K. C. Chen, S. S. Chang, H. J. Huang, T. L. Lin, Y. J. Wu, and C. Y. C. Chen, "Three-in-one agonists for PPAR-a, PPAR$\gamma$, and PPAR-d from traditional Chinese medicine," Journal of Biomolecular Structure and Dynamics, vol. 30, no. 6, pp. 662683, 2012.

[16] K. C. Chen, S. S. Chang, F. J. Tsai, and C. Y. Chen, "Han ethnicity-specific type 2 diabetic treatment from traditional Chinese medicine?" Journal of Biomolecular Structure \& Dynamics, vol. 31, no. 11, pp. 1219-1235, 2013.

[17] K. C. Chen and C. Yu-Chian Chen, "Stroke prevention by traditional Chinese medicine? A genetic algorithm, support vector machine and molecular dynamics approach," Soft Matter, vol. 7, no. 8, pp. 4001-4008, 2011.

[18] K. C. Chen, K. W. Chang, H. Y. Chen, and C. Y. C. Chen, "Traditional Chinese medicine, a solution for reducing dual stroke risk factors at once?" Molecular BioSystems, vol. 7, no. 9, pp. 2711-2719, 2011.
[19] K. C. Chen, M. F. Sun, S. C. Yang et al., "Investigation into potent inflammation inhibitors from traditional Chinese medicine," Chemical Biology \& Drug Design, vol. 78, no. 4, pp. 679-688, 2011.

[20] W. I. Tou, S. S. Chang, C. C. Lee, and C. Y. C. Chen, "Drug design for neuropathic pain regulation from traditional Chinese medicine," Scientific reports, vol. 3, p. 844, 2013.

[21] C. Y. C. Chen, “TCM Database@Taiwan: the world's largest traditional Chinese medicine database for drug screening in Silico," PLoS ONE, vol. 6, no. 1, Article ID e15939, 2011.

[22] C. Y. C. Chen and W. I. Tou, "How to design a drug for the disordered proteins?” Drug Discovery Today, vol. 18, no. 19-20, pp. 910-915, 2013.

[23] B. Xue, R. L. Dunbrack, R. W. Williams, A. K. Dunker, and V. N. Uversky, "PONDR-FIT: a meta-predictor of intrinsically disordered amino acids," Biochimica et Biophysica Acta-Proteins and Proteomics, vol. 1804, no. 4, pp. 996-1010, 2010.

[24] B. R. Brooks, R. E. Bruccoleri, B. D. Olafson et al., "CHARMM: a program for macromolecular energy minimization and dynamics calculations," Journal of Computational Chemistry, vol. 4, pp. 187-217, 1983.

[25] C. A. Lipinski, F. Lombardo, B. W. Dominy, and P. J. Feeney, "Experimental and computational approaches to estimate solubility and permeability in drug discovery and development settings," Advanced Drug Delivery Reviews, vol. 46, no. 1-3, pp. 3-26, 2001.

[26] C. M. Venkatachalam, X. Jiang, T. Oldfield, and M. Waldman, "LigandFit: a novel method for the shape-directed rapid docking of ligands to protein active sites," Journal of Molecular Graphics and Modelling, vol. 21, no. 4, pp. 289-307, 2003.

[27] B. Hess, C. Kutzner, D. van der Spoel, and E. Lindahl, "GRGMACS 4: algorithms for highly efficient, load-balanced, and scalable molecular simulation," Journal of Chemical Theory and Computation, vol. 4, no. 3, pp. 435-447, 2008.

[28] V. Zoete, M. A. Cuendet, A. Grosdidier, and O. Michielin, "SwissParam: a fast force field generation tool for small organic molecules," Journal of Computational Chemistry, vol. 32, no. 11, pp. 2359-2368, 2011.

[29] R. Fletcher, Optimization, Academic Press, New York, NY, USA, 1969. 

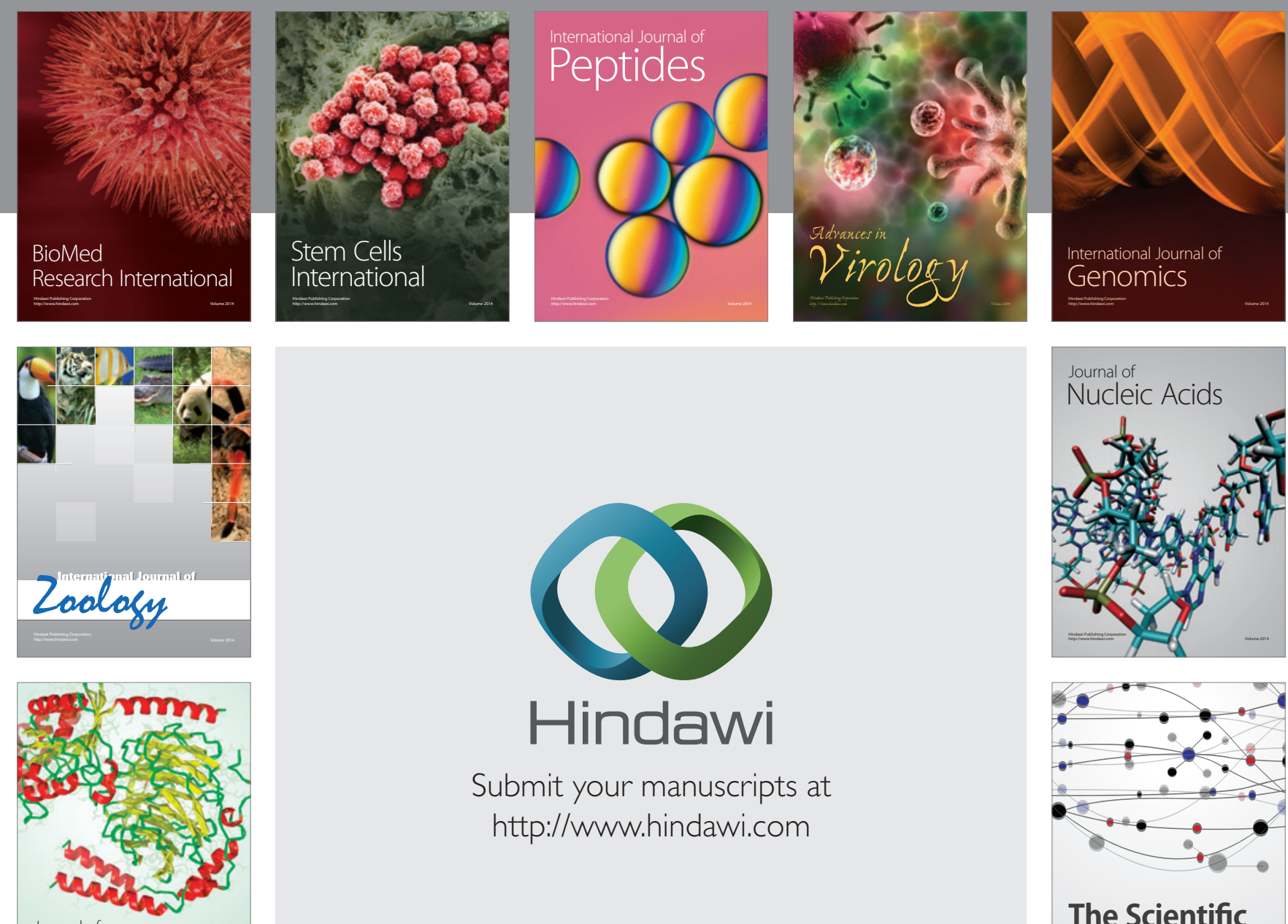

Submit your manuscripts at

http://www.hindawi.com

Journal of
Signal Transduction
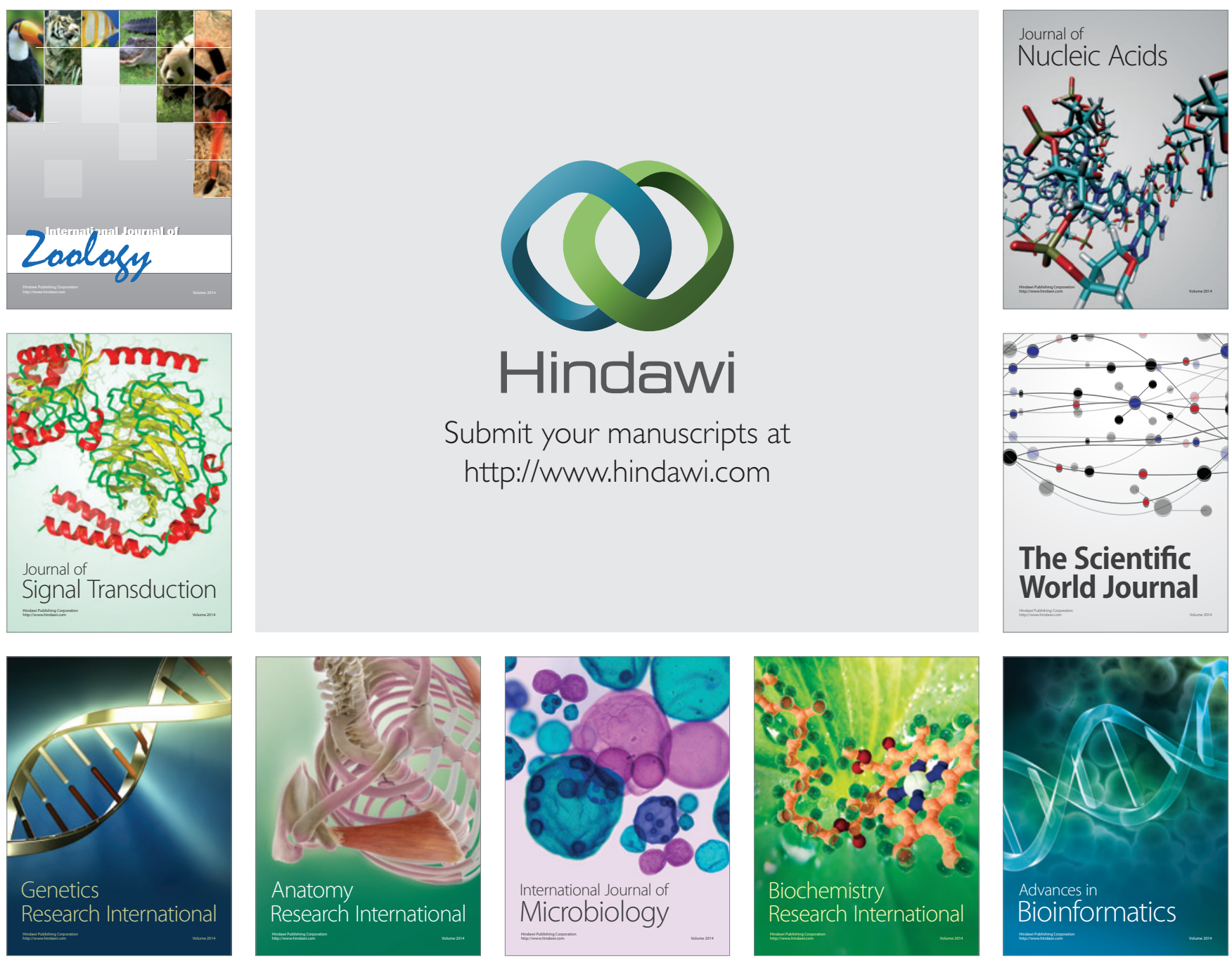

The Scientific World Journal
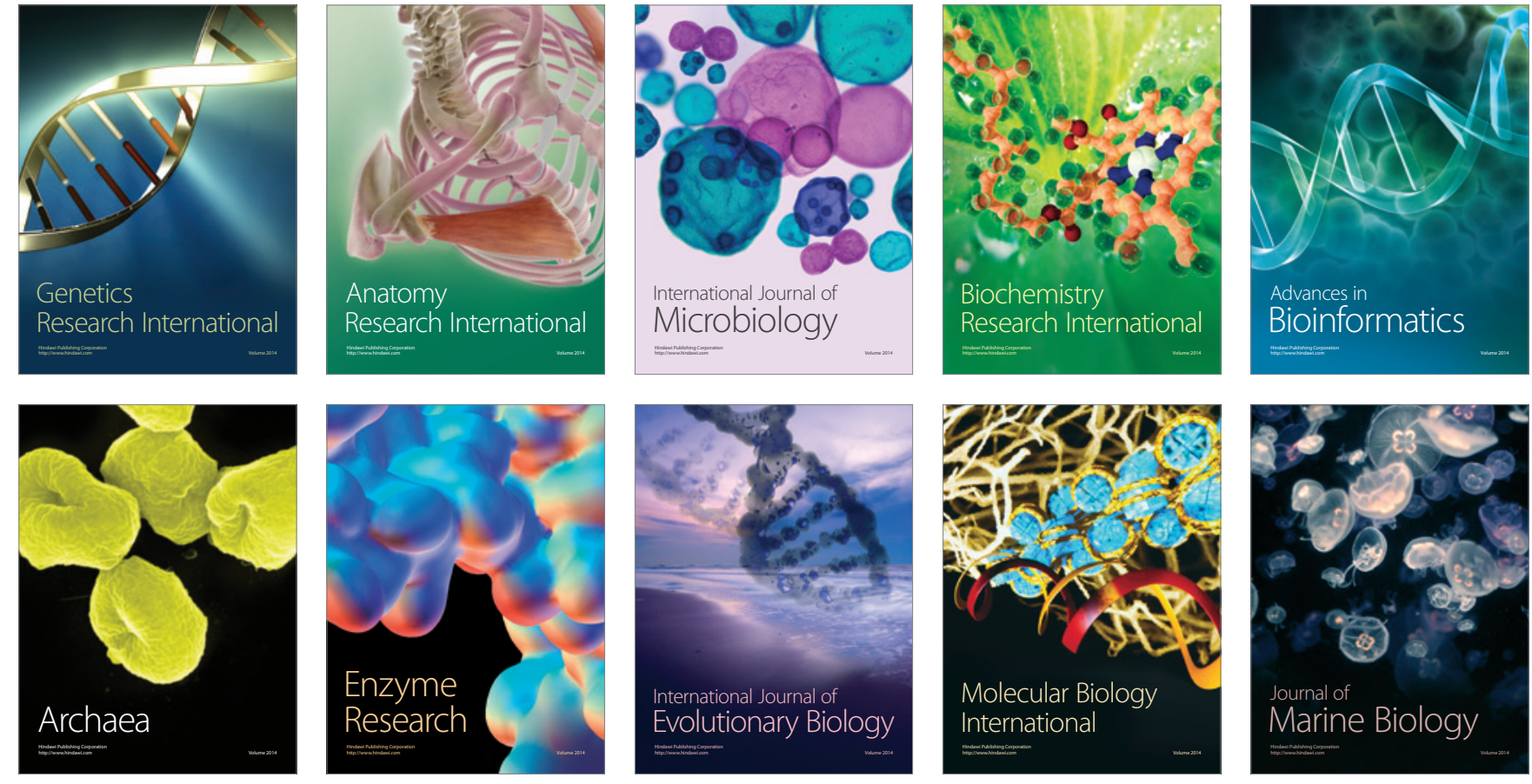